\title{
Vibration Reduction and Performance Enhancement in Rotorcraft Using Active Flaps at High Advance Ratios
}

\author{
Li Liu, Peretz P. Friedmann ${ }^{\dagger}$ Insung Kim ${ }^{\ddagger}$ and Dennis S. Bernstein ${ }^{\S}$ \\ Department of Aerospace Engineering, The University of Michigan, Ann Arbor, MI, 48109, USA
}

A computational study of helicopter vibration and rotor shaft power reduction is conducted using actively-controlled trailing-edge flaps (ACFs), implemented in both single and dual flap configurations. Simultaneous vibration reduction and performance enhancement is demonstrated under level flight condition at high advance ratios, where dynamic stall effects are significant. Power reduction is achieved using the adaptive Higher Harmonic Control (HHC) algorithm in closed loop, with 2-5/rev flap control harmonics. This approach is compared with an off-line, nonlinear optimizer available in MATLAB, and favorable comparisons are obtained. A parametric study of flap spanwise location is also conducted to determine its optimal location for power reduction. The effectiveness of ACF approach for power reduction is also compared with conventional individual blade control (IBC) approach. Rotor power reduction and simultaneous reduction of vibration and power are shown to be larger at higher rotor thrust and advance ratio. The simulation results clearly demonstrate the potential of the ACF system for power reduction as well as simultaneous vibration and power reduction.

\section{Nomenclature}

$\begin{array}{ll}c & \text { Blade chord } \\ c_{c} & \text { Flap chord } \\ C_{T} & \text { Rotor thrust coefficient } \\ \mathbf{D} & \text { Matrix defined to be } \mathbf{T}^{\mathrm{T}} \mathbf{Q T}+\mathbf{R} \\ F_{H X 4}, F_{H Y 4}, & \\ F_{H Z 4} & \text { Nondimensional } 4 / \mathrm{rev} \text { hub shears } \\ M_{H X 4}, M_{H Y 4}, & \\ M_{H Z 4} & \text { Nondimensional 4/rev hub moments } \\ M_{H z 1} & \text { Yawing moment about rotor hub } \\ N_{b} & \text { Number of rotor blades } \\ P_{R} & \text { Rotor shaft power } \\ \mathbf{Q} & \text { Weighting matrix for objectives to be reduced } \\ R & \text { Rotor blade radius } \\ \mathbf{R} & \text { Weighting matrix on control input } \\ \mathbf{T} & \text { Sensitivity, transfer matrix between control inputs and objective function } \\ \mathbf{u}_{k} & \text { Control input vector, } k^{\text {th }} \text { control step } \\ \mathbf{u}_{k, \text { opt }} & \text { Optimum value of control input vector } \\ x_{c} & \text { Spanwise location of center of control surface } \\ \mathbf{z}_{k} & \text { Objective vector, } k^{\text {th }} \text { control step } \\ \alpha & \text { Rotor disk angle of attack } \\ \alpha_{R} & \text { Relaxation coefficient for control algorithm }\end{array}$

\footnotetext{
*Postdoctoral Researcher, Member AIAA.

$\dagger$ François-Xavier Bagnoud Professor, Fellow AIAA, AHS

$¥$ Ph.D. Candidate, Student Member AIAA.

$\S$ Professor, Member AIAA.
} 


$\begin{array}{ll}\beta_{p} & \text { Blade precone angle } \\ \delta & \text { Flap deflection angle } \\ \delta_{N c}, \delta_{N s} & \text { N/rev cosine and sine amplitude of } \delta \\ \gamma & \text { Lock number } \\ \mu & \text { Helicopter advance ratio } \\ \Omega & \text { Rotor angular speed } \\ \omega_{F}, \omega_{L}, \omega_{T} & \text { Blade flap, lead-lag and torsional natural frequencies } \\ \psi & \text { Rotor azimuth angle } \\ \sigma & \text { Rotor solidity } \\ \theta_{\mathrm{tw}} & \text { Built-in twist angle }\end{array}$

\section{Introduction and Background}

Specifications for noise and vibration levels in rotorcraft are continuously increasing in stringency, Sthus motivating research related to active noise and vibration reduction. Desirable vibration levels have been identified to be below $0.05 \mathrm{~g}$ to provide passengers with "jet smooth" ride. A number of active control techniques have emerged for effective vibration reduction, ${ }^{1,2}$ as illustrated schematically in Fig. 1. These approaches generally fall into one of two categories: (a) active control approaches aimed at reducing vibrations in the rotor before they propagate into the fuselage, and (b) active control approaches implemented in the fuselage using an approach known as active control of structural response (ACSR). Within the first category of active control, where the primary objective is to reduce vibrations in the rotor, two approaches have emerged. These are (1) higher harmonic control (HHC) where the blades are activated in the nonrotating swashplate by introducing pitch commands, and (2) individual blade control (IBC) where each blade can be controlled independently in the rotating frame. Several implementations of IBC are available: (i) the conventional or earliest implementation based on pitch actuation at the blade root in the rotating system, (ii) actively controlled partial-span trailing-edge flaps, and (iii) the active-twist rotor where the entire blade is twisted by piezoelectric fiber embedded in the blade. Additional descriptions of these approaches can be found in Refs. 1 and 2.

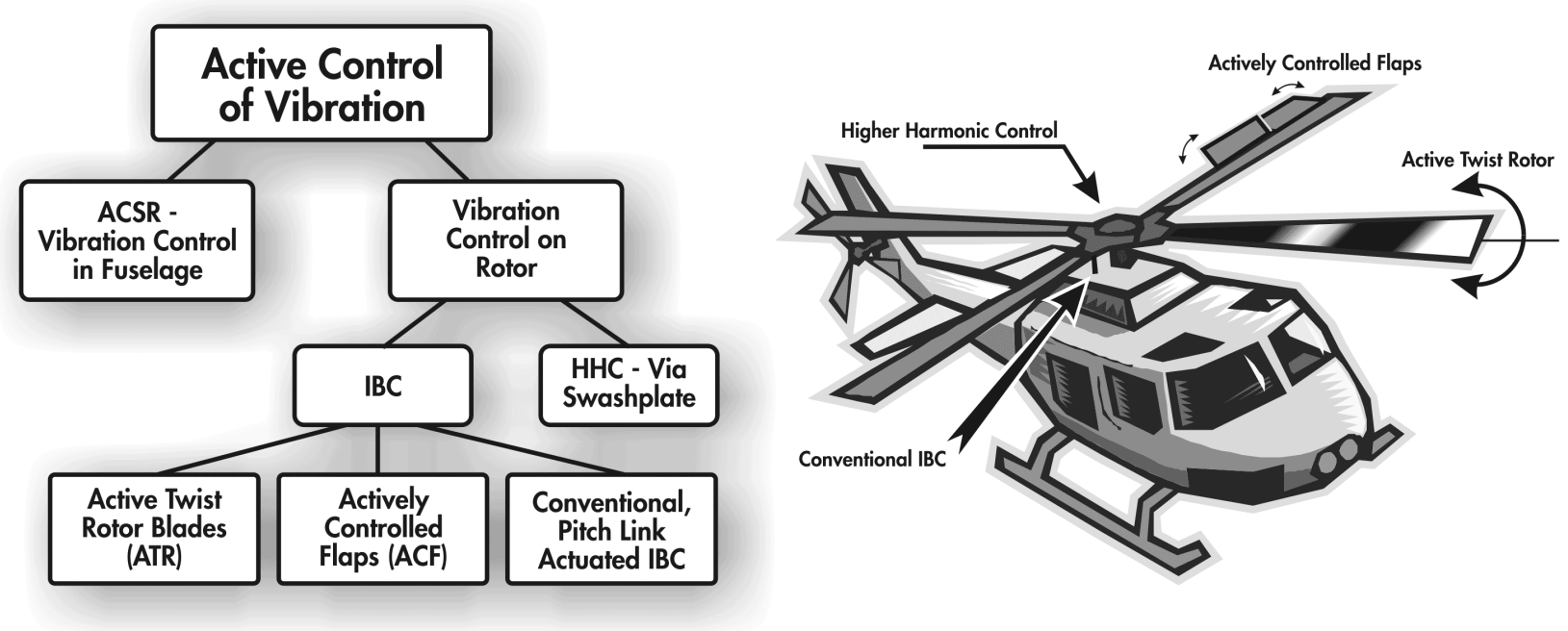

Figure 1. An Overview of Active Control Techniques.

Among these approaches the HHC and IBC were developed earlier and have been tested extensively in the wind tunnels as well as flight tests. Excellent vibration reduction of more than $80 \%$ has been demonstrated using these approaches. Subsequently, these approaches have also been considered for noise control, particularly in the blade vortex interaction (BVI) flight regime. Reduction of noise levels by 4-10dB, under BVI conditions, has been demonstrated in wind tunnel tests, on various helicopter configurations. ${ }^{3-5}$ It is important to note that these active control approaches have employed primarily what is known as the conventional HHC algorithm in rotorcraft community for vibration reduction. ${ }^{1,2,6,7}$ 
More recently, actively controlled flaps (ACFs) have emerged as an efficient means of the active control of vibration due to BVI as well as the alleviation of dynamic stall induced vibrations. ${ }^{1,8-16}$ In these studies the ACF system was implemented in both single and dual flap configurations and vibration reduction comparable to that achieved with HHC or conventional IBC was demonstrated without adverse effects on helicopter airworthiness. Furthermore, the ACF system has significantly lower power requirement, when compared to the blade root actuation approaches. ${ }^{1}$ Wind tunnel tests have also shown the feasibility of the ACF for vibration reduction. ${ }^{16,17}$ During the Smart Material Actuated Rotor Technology (SMART) program conducted by Boeing, ${ }^{18,19}$ a full scale piezoelectrically actuated flap system for vibration and noise control for a fivebladed bearingless MD-900 rotor has been tested on a whirl tower to demonstrate control effectiveness. In Europe, a full scale BK117 with three actively controlled, piezoelectrically actuated flaps has been flight tested by Eurocopter Germany in the open loop mode on September 6, 2005 and additional flight tests, including closed loop test, are currently in progress. ${ }^{20}$

In Refs. 11-13, the effectiveness of ACF system to reduce the vibrations in the high advance ratio flight regime, where dynamic stall effects are known to be important, was studied by Depailler and Friedmann. The simulation indicated that ACF was successful in alleviating dynamic stall induced vibrations, thus demonstrating the capability of the ACF systems to reduce vibrations due to multiple sources. Recently, a comprehensive helicopter simulation code was developed using a unified approach for the prediction and active control of vibratory loads and blade-vortex interaction noise. ${ }^{21-25}$ Considerable potential for active noise reduction and simultaneous vibration and noise reduction have been demonstrated using actively controlled flaps with $2-5 / \mathrm{rev}$ components on a rotor resembling the MBB BO-105 hingeless rotor. ${ }^{22,23}$ The capability of the ACF system has also been demonstrated using a bearingless rotor configuration resembling the MD-900 rotor in Ref. 24.

Despite the vibration and noise reduction demonstrated in experiments and numerical simulations, these active control techniques are still in preliminary flight test stages. ${ }^{26}$ Concerns associated with cost of implementation, interference with the primary flight controls, and the potential power penalties for operating the helicopter have prevented the actual implementation of such devices on a production helicopter. Clearly further study of such active control devices is needed, so as to reap the largest potential benefit on the sizeable cost associated with installing such active control systems in a production helicopter. One of the most important considerations when deploying active noise and vibration control systems is the prevention of any performance penalty that can be caused by the system. Equally important is the potential for performance enhancement with an active control device which would provide justification for compensating for the cost of the system.

A wind tunnel study by Shaw et. al. ${ }^{27}$ which was intended primarily to demonstrate the effectiveness of HHC system for vibration reduction, also provided a preliminary assessment of the system for performance enhancement. The test was conducted on a scaled three-bladed CH-47D rotor, at two cruise airspeed conditions of 135 knots and 160 knots $(\mu \approx 0.30$ and 0.35$)$, respectively. Pure $2 /$ rev HHC inputs with $2^{\circ}$ amplitude were used for performance enhancement, and the optimal phase angle was determined experimentally, by trial and error. It was found that the power required in trim was reduced substantially by $6 \%$ at 135 knots and $4 \%$ at 160 knots. In another study, full-scale wind tunnel tests of a MBB BO-105 rotor were conducted at NASA Ames in the $40 \times 80$ foot wind tunnel. ${ }^{4,28}$ An IBC system was tested in the open-loop for vibration and noise reduction as well as rotor power reduction. Rotor power reductions of up to $7 \%$ were demonstrated using $2 /$ rev IBC at advance ratios of 0.40 and 0.45 , however, no power reduction could be achieved at advance ratio of 0.30 .

An analytical study conducted by Nguyen and Chopra ${ }^{29}$ examined the effects of HHC on a scaled threebladed rotor similar to the one tested in Ref. 27. A power reduction of $3.8 \%$ was obtained using $2 / \mathrm{rev}$ HHC inputs with $2^{\circ}$ amplitude. Cheng and $\mathrm{Celi}^{30}$ performed a computational study of power reduction using $2 /$ rev HHC inputs. The rotor model used was fairly simple, with rigid blade dynamics and a dynamic inflow model. The study noted that rotor power reductions were possible when using properly phased open-loop HHC input, at an advance ratio of $\mu=0.3$. Reference 30 was based on table look-up aerodynamics and a nonlinear drag model; and it was emphasized that power reductions could only be obtained by simulation when a nonlinear drag model was used. A subsequent study by the same authors used numerical optimization techniques to determine the optimal $2 / \mathrm{rev}$ input, and included a free wake model. ${ }^{31}$ With the addition of free wake, the amount of power reduction that could be simulated was almost eliminated.

Performance enhancement using the ACF approach has only been attempted in a few studies thus far. A model rotor equipped with cam operated trailing edge flaps was tested in wind tunnel by Straub. ${ }^{32}$ Effect 
on rotor performance with $2 / \mathrm{rev}$ flap actuation was evaluated at advance ratios of 0.25 and 0.30 , but the results were considered inconclusive due to issues associated with the accuracy of the measurements obtained during the test. A preliminary computational study on rotor power reduction for a rotor resembling the MBB BO-105 was conducted in Ref. 25. In this study a single flap configuration with deflections limited to $4^{\circ}$ degrees was examined in the open loop mode, under BVI conditions at $\mu=0.15$. It was found that power reduction could only be obtained when the fundamental torsional frequency of the rotor was reduced from the actual value of the MBB BO-105 rotor to a lower value of $2.5 / \mathrm{rev}$.

When using an ACF for vibration or noise reduction the deflections of the flap increase the drag of the blade and therefore vibration and noise reduction are usually accompanied by a performance penalty. The fundamental question is therefore whether it is possible to use the ACF system without incurring a power penalty. Motivated by this desire the overall objective of the paper is to examine simultaneous vibration reduction and performance enhancement using the ACF based approach. Rotor power reduction using ACF approach, employing the HHC algorithm in the closed loop, will be emphasized. Based on the concise review of previous research provided in this introduction on rotor power reduction, the rotor power reduction problem at advance ratios of higher than $\mu=0.35$ will be considered, since this is of primary interest in cruise condition. While the noise aspect associated with this problem is also of interest, the noise emissions at such advance ratios are typically dominated by high speed impulsive (HSI) noise ${ }^{33}$ and this problem is computationally very intensive and therefore will be considered in follow-on research. The specific objectives of the paper are summarized below:

- assess the potential for rotor power reduction using the ACF system by applying the HHC control algorithm;

- examine the mutual interaction between power reduction and vibration reduction;

- explore the potential of simultaneous power and vibration reduction using the ACF system;

- determine the sensitivity of power reduction to flap spanwise locations;

- compare the effectiveness for power reduction using the ACF approach with conventional IBC approach;

- explore the effect of flight conditions such as rotor thrust and forward flight speed on the power reduction capability of the ACF system;

- conduct a study of power reduction, vibration reduction as well as simultaneous reduction using off-line nonlinear optimizers, and compare the results with those obtained using the HHC algorithm.

Achieving reduced vibration or noise levels without undue performance penalty is central for the practical implementation of the ACF system; and it has a key role governing the feasibility of implementing an ACF system in a practical setting.

\section{Mathematical Model}

The present study is based on a comprehensive rotorcraft aeroelastic analysis tool that accounts for the effects of dynamic stall at high advance ratios, as described in detail in Refs. 11-13. The power reduction studies conducted in the present research will be carried out at advance ratios of higher than 0.35 , where the dynamic stall effects are important. The fundamental ingredients of the aeroelastic model are concisely summarized in the following subsections.

\section{A. Structural Dynamic Model}

The structural dynamic model consists of an isotropic hingeless rotor blade, which is cantilevered at the hub and has fully coupled flap-lag-torsional dynamics including nonlinearities due to moderate blade deflections. ${ }^{8}$ The aeroelastic model is capable of simulating rotors with single or dual actively controlled partial span trailing edge flaps mounted on the rotating blade as depicted in Fig. 1. The equations of motion are discretized using the global Galerkin method, based upon the free vibration modes of the rotating blade. Three flapping modes, two lead-lag modes and two torsional modes are used when computing the numerical results given in the results section. 


\section{B. Aerodynamic Model}

Blade section aerodynamic loads for attached flow are calculated using a rational function approximation (RFA) approach as described in Ref. 9. The RFA approach is a two-dimensional, unsteady time-domain aerodynamic theory that accounts for compressibility, variations in the oncoming velocity and a bladeflap combination. Aerodynamic cross-sectional loads consisting of lift, moment and flap-hinge moment are calculated, together with chordwise pressure distribution ${ }^{21}$ which is required in acoustic calculations. The RFA model for the blade-flap combination is linked to a free wake model, ${ }^{10}$ which produces non-uniform inflow distribution. For the separated flow regime, unsteady aerodynamic loads are calculated using the ONERA dynamic stall model described by Petot. ${ }^{34}$ The augmented aerodynamic states associated with RFA attached flow states and ONERA separated flow states are combined to produce the time-domain, state space aerodynamic model. Furthermore, a simple, linear drag model that accounts for additional drag due to flap deflection, that increases the power required for the rotor to operate, is also implemented. ${ }^{12}$

\section{Solution Procedure}

The combined structural and aerodynamic equations form a system of coupled differential equations that can be cast in state variable form. They are then integrated in the time domain using the Adams-Bashforth $\mathrm{DE} / \mathrm{STEP}$ predictor-corrector algorithm. A propulsive trim procedure is implemented in level flight condition; where six equilibrium equations (three forces and three moments) are enforced. The trim equations are solved in a coupled manner with the aeroelastic equations of motion. Hub vibratory loads are obtained by integrating the distributed aerodynamic and inertial loads over the blades. Average rotor power is defined as the instantaneous power required to drive the rotor at a constant angular velocity $\Omega$ averaged over one revolution,

$$
P_{R}=\frac{\Omega}{2 \pi} \int_{0}^{2 \pi}-M_{H z 1}(\psi) d \psi,
$$

where $M_{H z 1}$ is the total yawing moment about the hub and includes the effect of unsteadiness, compressibility, dynamic stall (if applicable), and the additional drag due to flap deflection. The negative sign in front of $M_{H z 1}(\psi)$ is due to the fact that it represents the torque about the rotor shaft due to the loading on the blades, and therefore the engine must supply a torque equal to $-M_{H z 1}(\psi)$ to maintain a constant angular velocity. ${ }^{8}$ Equation 1 is a general expression valid for blades with or without actively controlled flaps.

\section{Control Strategies}

The Higher Harmonic Control (HHC) algorithm ${ }^{6,7,14}$ has been used successfully for both vibration and noise reduction; as well as simultaneous vibration and noise reduction. Furthermore, several variants of this algorithm, including a relaxed and an adaptive version, have been shown to improve the robustness of the algorithm. ${ }^{7}$ An adaptive form of this algorithm was successfully applied in the closed loop noise control as well as simultaneous vibration and noise control in Ref. 22. In the present study, the adaptive $\mathrm{HHC}$ algorithm is used for rotor power reduction, where the objective function consists of averaged rotor power over one revolution. For simultaneous reduction of vibration and power, a combined objective which consists of vibration and power components is used, and an appropriate weighting matrix is used to adjust the control effort so as to achieve a desirable balance between vibration and power objectives. For the practical implementation of the algorithm, an appropriate control input weighting is chosen such that the maximum flap deflection does not exceed $4^{\circ}$.

The HHC algorithm has been the subject of a recent paper, ${ }^{7}$ wherein the stability, robustness, and convergence properties of the algorithm together with a number of variants are addressed in detail. This algorithm is based on a linear, quasi-static, frequency domain representation of helicopter response to control inputs. The inputs to the algorithm are comprised of a combination of flap deflection harmonics with discrete frequencies of $N_{\min }-N_{\max } /$ rev. The total flap deflection is given as

$$
\delta(\psi)=\sum_{N=N_{\min }}^{N_{\max }}\left[\delta_{N c} \cos (N \psi)+\delta_{N s} \sin (N \psi)\right]
$$

For a four-bladed rotor, the flap deflection harmonics typically consist of 2-5/rev components for vibration reduction, as well as in noise control. ${ }^{22}$ Most studies thus far have only examined the effects of $2 / \mathrm{rev}$

$$
5 \text { of } 19
$$

American Institute of Aeronautics and Astronautics 
component for power reduction using open loop; ${ }^{27,30,31}$ however, in the present study this limitation is removed and the whole range of harmonics from $2-5 /$ rev will be used since the feedback controller based on the HHC algorithm is capable of choosing the most effective harmonic components for power reduction. These flap deflections are related to the vibration or noise level magnitudes through a transfer matrix $\mathbf{T}$, given by

$$
\mathbf{T}=\frac{\partial \mathbf{z}_{k}}{\partial \mathbf{u}_{k}}
$$

The control strategy is based on the minimization of a performance index that was originally developed for vibration reduction ${ }^{6}$ which is a quadratic function of the quantities that are being reduced (vibration or noise) $\mathbf{z}_{k}$ and control input amplitudes $\mathbf{u}_{k}$ :

$$
J\left(\mathbf{z}_{k}, \mathbf{u}_{k}\right)=\mathbf{z}_{k}^{\mathrm{T}} \mathbf{Q} \mathbf{z}_{k}+\mathbf{u}_{k}^{\mathrm{T}} \mathbf{R} \mathbf{u}_{k},
$$

The subscript $k$ refers to the $k^{\text {th }}$ control step, reflecting the discrete-time nature of the control. The time interval between each control step must be sufficient to allow the system to return to the steady state, typically in 3-5 revolutions, so that the vibration or power levels can be accurately measured. The optimal control law is given by:

$$
\mathbf{u}_{k, \text { opt }}=-\mathbf{D}^{-1} \mathbf{T}^{\mathrm{T}} \mathbf{Q}\left\{\mathbf{z}_{0}-\mathbf{T} \mathbf{u}_{0}\right\}
$$

where

$$
\mathbf{D}=\mathbf{T}^{\mathrm{T}} \mathbf{Q} \mathbf{T}+\mathbf{R}
$$

For a well-identified linear system the algorithm converges to the optimum value in a single step. ${ }^{7}$ However, if the rotor cannot be modeled as a perfectly linear system, the optimal value will not be reached after the first step. The convergence issue of the algorithm was addressed in Ref. 7, where a relaxed version of the algorithm, described concisely below, was developed. Traditionally, the control input update is represented in iterative form as shown in Eq. (7):

$$
\mathbf{u}_{\mathrm{k}+1}=\mathbf{u}_{\mathrm{k}}+\Delta \mathbf{u}_{\mathrm{k}}
$$

In the relaxed variant of the algorithm, a relaxation factor $\alpha_{R}$ is introduced,

$$
\mathbf{u}_{\mathrm{k}+1}=\mathbf{u}_{\mathrm{k}}+\alpha_{R} \Delta \mathbf{u}_{\mathrm{k}},
$$

where $0<\alpha_{R}<1$. This has been shown to increase the robustness of the algorithm at the expense of convergence speed. ${ }^{7}$ An adaptive version ${ }^{6,7}$ of the HHC algorithm was also shown to be useful in the noise reduction studies in the presence of stronger nonlinearities, therefore it is also applied in this study for power control. In the adaptive variant, the transfer matrix $\mathbf{T}$ is identified online, using a recursive least-squares technique, following the method described in Ref. 7.

For vibration reduction (VR) studies, the vector $\mathbf{z}_{k}$ consists of $4 /$ rev vibration levels as represented by hub shears and moments, given in Eq. (9),

$$
\mathbf{z}_{k, \mathrm{VR}}=\left[\begin{array}{c}
F_{H X 4} \\
F_{H Y 4} \\
F_{H Z 4} \\
M_{H X 4} \\
M_{H Y 4} \\
M_{H Z 4}
\end{array}\right]
$$

When the controller is used for power reduction the objective vector $\mathbf{z}_{k}$ is simply averaged rotor shaft power as given in Eq. (1).

$$
\mathbf{z}_{k, \mathrm{PR}}=\left[P_{R}\right]
$$

For simultaneous reduction (SR) problems, a combined output vector is defined

$$
\mathbf{z}_{k, \mathrm{SR}}=\left[\frac{\mathbf{z}_{k, \mathrm{VR}}}{\mathbf{z}_{k, \mathrm{PR}}}\right] .
$$

$$
6 \text { of } 19
$$


The weighting matrix $\mathbf{Q}$ is used to adjust the control effort so as to achieve a desirable balance between the vibration levels and power reductions.

In order to evaluate the effectiveness of the HHC algorithm under the high speed forward flight conditions, where strong nonlinearities associated with the onset of dynamic stall are present, the aeroelastic simulation code is coupled with MATLAB so as to utilize built-in nonlinear optimization solvers to find potentially lower controlled values using the same active flap configurations. The nonlinear least squares optimizer LSQNONLIN, which is a subspace trust region method and is based on the interior-reflective Newton method described in Refs. 35 and 36, was selected for this purpose. This approach is suitable for offline identification of best possible vibration and rotor power reduction, using the ACF approach. The results obtained using the online adaptive HHC algorithm, which is computationally much more efficient, are compared with those obtained with LSQNONLIN to determine the performance of the algorithm. The results obtained with the offline optimizer represent the best possible performance enhancement that can be achieved.

\section{Results}

The results presented in this section were obtained for a helicopter configuration resembling a fullscale MBB BO-105 helicopter with a four-bladed hingeless rotor system. The properties of the helicopter configuration used in the computations are summarized in Table 1. The characteristics of the actively controlled flap configurations are given in Table 2, including a single servo flap configuration and a dual servo flap configuration. Most of the results are obtained for level flight condition at a relatively high advance ratio of $\mu=0.35$, however one set of results is obtained for a higher advance ratio, $\mu=0.40$. Propulsive trim is used to trim the rotor to force and moment equilibrium in space, for a thrust level of $C_{T} / \sigma=0.0714$, unless otherwise specified.

Table 1. MBB BO-105 hingeless blade configuration.

\begin{tabular}{ll}
\hline \hline$\underline{\text { Rotor Data }}$ & \\
$N_{b}=4$ & $c=0.05498 L_{b}$ \\
$\omega_{F}=1.12,3.41,7.62$ & $C_{d o}=0.01$ \\
$\omega_{L}=0.73,4.46$ & $C_{m o}=0.0$ \\
$\omega_{T}=3.17$ & $a_{o}=2 \pi$ \\
$\theta_{\mathrm{tw}}=-8^{\circ}$ & $\theta_{\mathrm{FP}}=6.5^{\circ}$ \\
$\gamma=5.5$ & $\sigma=0.07$ \\
$\beta_{p}=2.5^{\circ}$ & \\
Helicopter Data & \\
\hline$C_{T} / \sigma=0.0714$ & $\mu=0.35$ \\
$L_{b}=4.91 \mathrm{~m}$ & $\Omega=425 \mathrm{RPM}$ \\
\hline \hline
\end{tabular}

Table 2. Flap configuration.

\begin{tabular}{ll}
\hline \hline$c_{c}=0.25 c$ & \\
$\frac{\text { Single Servo Flap }}{x_{c}=0.75 L_{b}}$ & \\
$\frac{L_{c}=0.12 L_{b}}{x_{c}^{1}=0.72 L_{b}}$ & \\
$x_{c}^{2}=0.92 L_{b}$ & $L_{c}^{1}=0.06 L_{b}$ \\
\hline
\end{tabular}

Table 3. Summary of rotor power reduction during Power Reduction (PR) and Simultaneous Reduction(SR), $C_{T} / \sigma=0.0714, \mu=0.35$.

\begin{tabular}{l|ccc|ccc}
\hline \hline Objective & \multicolumn{3}{|c|}{ Power Reduction(PR) } & \multicolumn{3}{c}{ Simultaneous Reduction(SR) } \\
\hline Controller & \multicolumn{2}{|c}{ HHC } & LSQNONLIN & \multicolumn{2}{c}{ HHC } & LSQNONLIN \\
Flap Config. & Single & Dual & Single & Single & Dual & Single \\
Baseline Power & 0.00670286 & 0.00681677 & 0.00670286 & 0.00670286 & 0.00681677 & 0.00670286 \\
Controlled & 0.00658692 & 0.00669656 & 0.00654460 & 0.00667611 & 0.00677104 & 0.00663603 \\
Reduction(\%) & 1.73 & 1.76 & 2.36 & 0.40 & 0.67 & 1.00 \\
\hline \hline
\end{tabular}




\section{A. Rotor Power Reduction}

In this section the potential of the ACF approach for rotor power reduction is explored. First the adaptive higher harmonic control (HHC) algorithm is used for rotor power control. The effect of power reduction on vibratory loads is also examined during power reduction. The results for rotor power reduction are summarized in Table 3.

As shown in Table 3, the rotor power can be reduced by $1.73 \%$ and $1.76 \%$ compared to the baseline, using the single and dual flap configurations, respectively. This reduction is achieved in the presence of dynamic stall, which is important under the simulated flight condition at $\mu=0.35$. Note that the baseline power is slightly higher for the dual flap case, under the same rotor trim settings. During the power reduction the maximum flap deflections required by the controller are less than $3^{\circ}$, as shown in Fig. 2. It should be emphasized that the pitch input has a large $3 /$ rev harmonic component, which suggests that the pure $2 /$ rev control harmonic employed by earlier studies ${ }^{27,30,31}$ may not always be the best component for power reduction. Furthermore, it can be seen that the flap deflections of the two flaps are similar in the dual flap configuration, which also resemble the flap deflection for the single flap case.
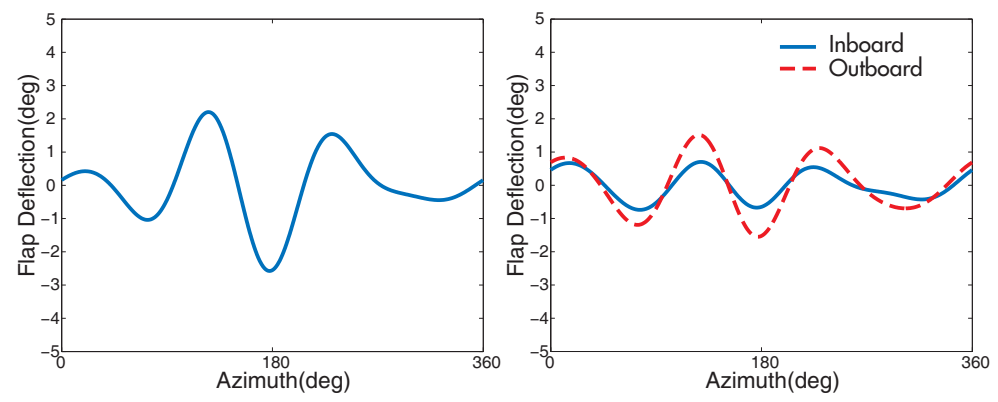

Figure 2. Flap deflection during power reduction, $\mathbf{C}_{\mathbf{T}} / \sigma=0.0714, \mu=0.35$.

Figure 3 illustrates that the vibratory loads during power reduction increase substantially; by more than $100 \%$, for both the single and dual flap configurations. This suggests that rotor power as a single objective for the controller results in unacceptable vibration levels. Therefore, an alternative combined objective function which accounts for both vibration and power is required, such an approach is considered next.

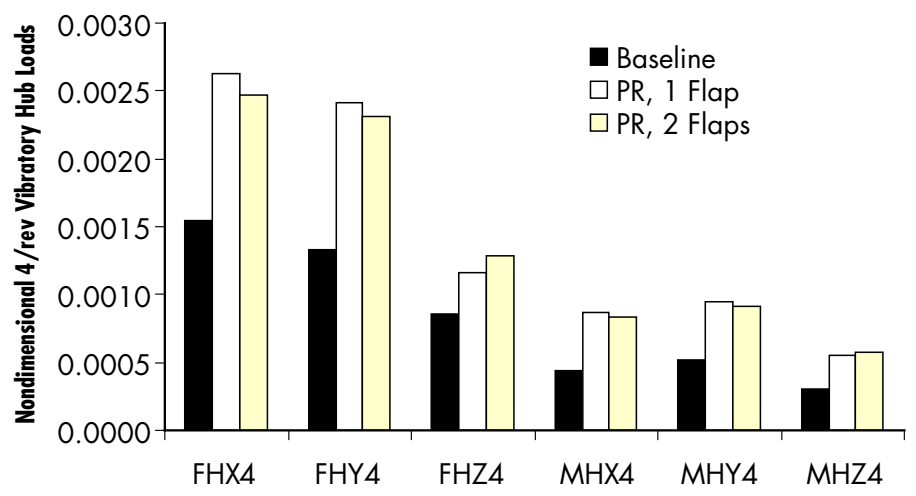

Figure 3. Vibration levels during power reduction, $\mathbf{C}_{\mathbf{T}} / \sigma=0.0714, \mu=0.35$.

\section{B. Simultaneous Vibration and Rotor Power Reduction}

In this section, a composite objective function which consists of a combination of vibratory loads and rotor power components is used together with the HHC algorithm, so as to achieve simultaneous reduction of both vibration and power. The results shown are obtained using a weighting matrix: the vibratory hub shear components are weighted by a factor of 1 , while the vibratory hub moments and rotor power components are weighted by a factor of 10 . The rotor and flap configurations as well as flight conditions are identical to those used in the previous section. 
Table 3 shows rotor power reduction of about $0.4 \%$ and $0.67 \%$ for the simultaneous control, using the single and dual flap configurations, respectively. Obviously the amount of power reduction that can be achieved for the combined objective is smaller than what has been obtained with the controller tuned for power reduction alone. The maximum flap deflections for these cases are less than $3^{\circ}$, as shown in Fig. 4 . It is interesting to note that $2 / \mathrm{rev}$ harmonic is the major component for the simultaneous reduction case.
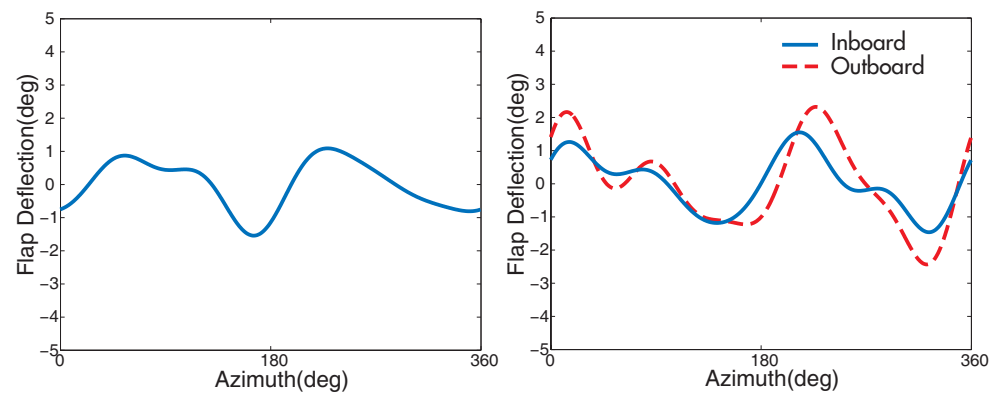

Figure 4. Flap deflection during simultaneous reduction, $\mathbf{C}_{\mathbf{T}} / \sigma=0.0714, \mu=0.35$.

The reduction of the vibratory loads during power reduction is shown in Fig. 5. For the single flap case, the individual hub shear and moment components are reduced between $28-78 \%$, while the vibration objective is reduced by $68 \%$. The combined vibration and power objective is reduced by $3.6 \%$. Despite a slightly better power reduction during vibration suppression, the dual flap configuration produces slightly less vibration reduction compared to the single flap case. From these results, it can be seen that the ACF is capable of producing significant vibration reduction along with a small amount of power reduction, using small flap deflections of less than $3^{\circ}$.

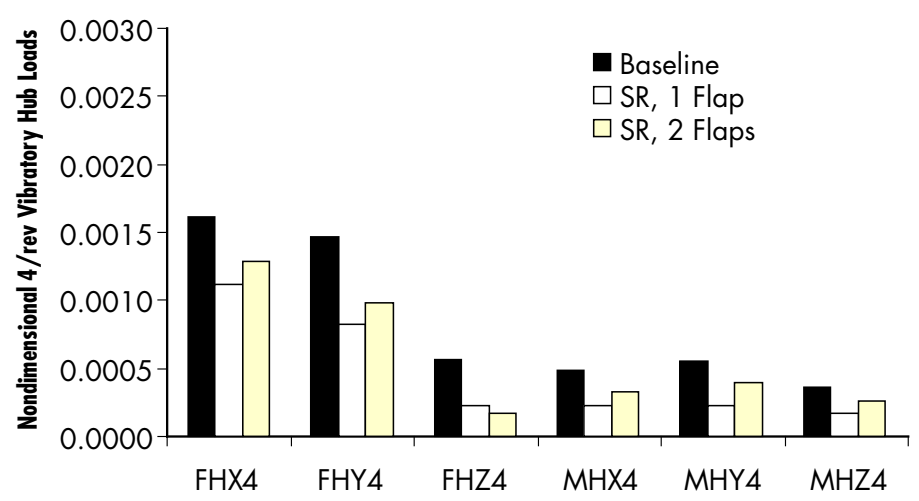

Figure 5. Vibration levels during simultaneous vibration and power reduction, $\mathbf{C}_{\mathbf{T}} / \sigma=0.0714, \mu=0.35$.

\section{Vibration and Rotor Power Reduction Using the Off-line Optimizer LSQNONLIN}

In this section the results obtained using the nonlinear optimizer LSQNONLIN available in the MATLAB package are shown for vibration and power reduction. These results are compared to those obtained previously using the adaptive HHC algorithm, to determine its effectiveness. In the optimization of a nonlinear objective function local minima for vibration or power can be obtained during the search, therefore different flap inputs are applied as initial conditions. Ten initial flap inputs are generated randomly with the constraint that the maximum flap deflections not exceed $4^{\circ}$. The best optimization results using LSQNONLIN are chosen among these ten flap initial inputs along with the case with zero flap initial deflection.

The nonlinear optimizer LSQNONLIN is capable of achieving rotor power reduction of $2.36 \%$, as shown in Table 3. This is superior to that achieved using the adaptive HHC algorithm; however, the performance of the adaptive HHC algorithm is reasonably good in addition to its numerical efficiency. The flap deflections required by the optimizer are shown in Fig. 6, where the maximum flap deflection is limited to be less than $4^{\circ}$. Similar to the flap deflections shown in Fig. 2 the $3 /$ rev harmonic is the major component, although 
the $2 /$ rev harmonic also has a significant contribution. The vibration levels during power reduction are also increased significantly, shown in Fig. 7, which is similar to the results shown earlier using the HHC algorithm.

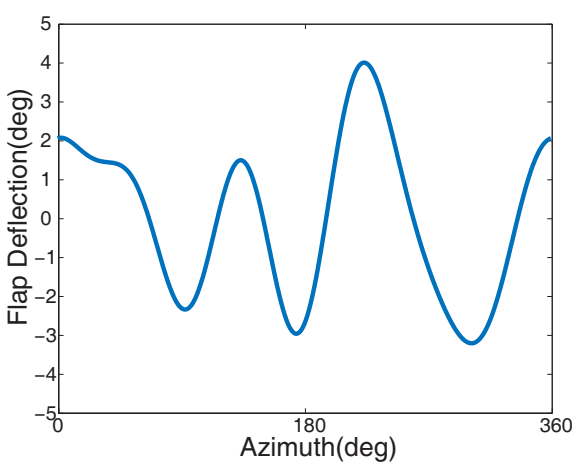

Figure 6. Flap deflection during power reduction using nonlinear optimizer LSQNONLIN, $\mathbf{C}_{\mathbf{T}} / \sigma=0.0714$, $\mu=0.35$.

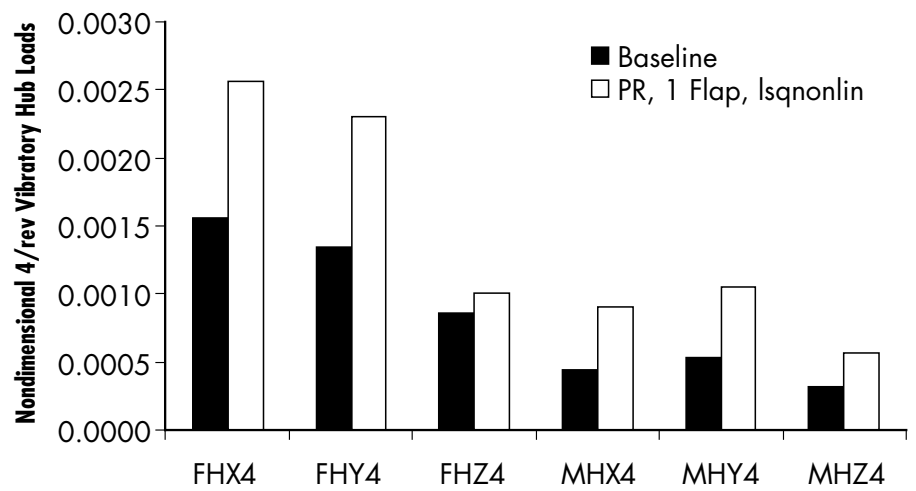

Figure 7. Vibration levels during power reduction using nonlinear optimizer LSQNONLIN, $\mathbf{C}_{\mathbf{T}} / \sigma=\mathbf{0 . 0 7 1 4}$, $\mu=0.35$.

For simultaneous vibration and power reduction, the rotor power is reduced by $1.0 \%$ as shown in Table 3 and the vibration objective is reduced by $55 \%$ as shown in Fig. 9. The flap deflections are shown in Fig. 8 and it is evident that flap deflections are less than $4^{\circ}$. It should be noted that a weighting matrix different from the one used in the HHC algorithm shown earlier is employed here: all the vibratory hub shear components are weighted by a factor of 1 , while the rotor power components are weighted by a factor of 5 . This weighting matrix puts more emphasis on power objective compared to the one used in the HHC algorithm. As a result, the degree of power reduction using LSQNONLIN is larger than that obtained using the HHC algorithm, whereas the degree of vibration reduction is slightly less than that found with the HHC algorithm. It is important to note that the flap deflections for simultaneous vibration and power reduction are quite similar in overall shape, despite different amplitude, to those shown in Fig. 4, reflecting the fact that the $2 /$ rev harmonics are the dominant components.

\section{Comparison of HHC to LSQNONLIN}

A plot of the vibration objective $J_{\text {vib }}$ versus the power objective $J_{\text {power }}$ is depicted in Fig. 10. The figure shows the tradeoff between the competing objectives at all control steps for both LSQNONLIN and HHC algorithms. The blue circles represent the values of the objectives at all function evaluations during the course of optimization using LSQNONLIN. The boundary of these objectives, represented by the red line, shows an approximate Pareto-optimal curve illustrating the best tradeoff between the two competing objectives. The grey, black and green lines represent the power reduction, vibration reduction and simultaneous reduction using the HHC algorithm from the same baseline, respectively. It is quite interesting to note that the optimal vibration reduction that can be obtained using HHC reaches the Pareto optimal curve obtained from LSQNONLIN. Moreover, the best simultaneous vibration and power reduction can be achieved with 


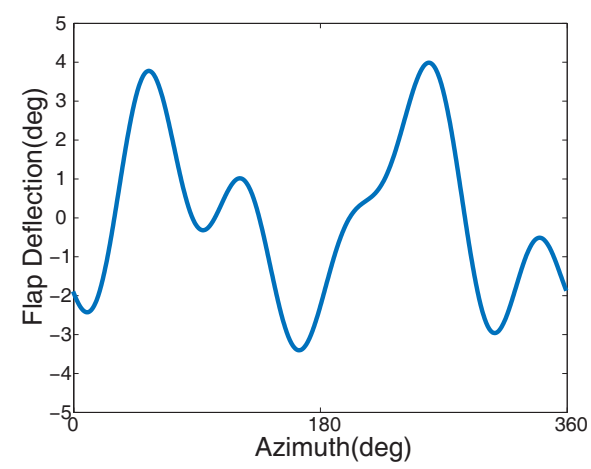

Figure 8. Flap deflection during simultaneous reduction using nonlinear optimizer LSQNONLIN, $\mathbf{C}_{\mathbf{T}} / \sigma=\mathbf{0 . 0 7 1 4}, \mu=\mathbf{0 . 3 5}$.

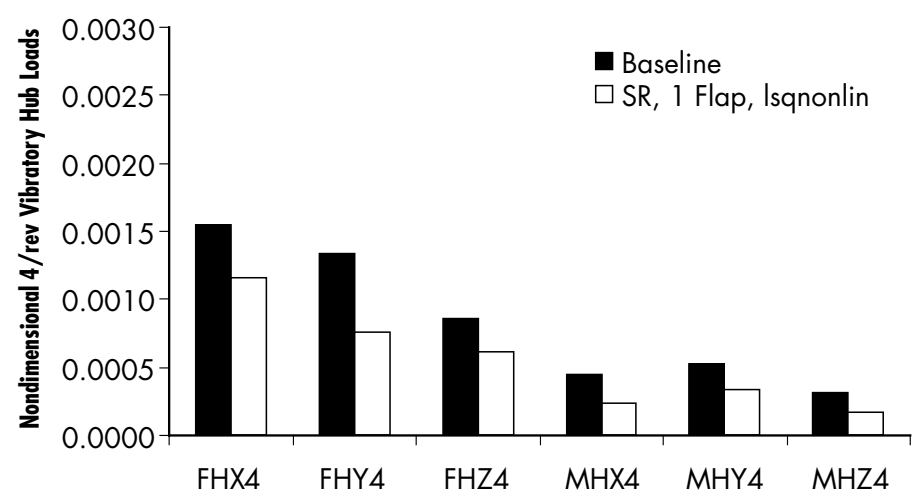

Figure 9. Vibration levels during simultaneous power and vibration reduction using nonlinear optimizer LSQNONLIN, $\mathbf{C}_{\mathbf{T}} / \sigma=0.0714, \mu=0.35$. 
HHC also approaches the optimal trade-off curve. However, it is evident that improved power reduction is obtained using LSQNONLIN, as shown in Fig. 10. Overall, the performance of the HHC algorithm is quite good particularly when considering its numerical efficiency.

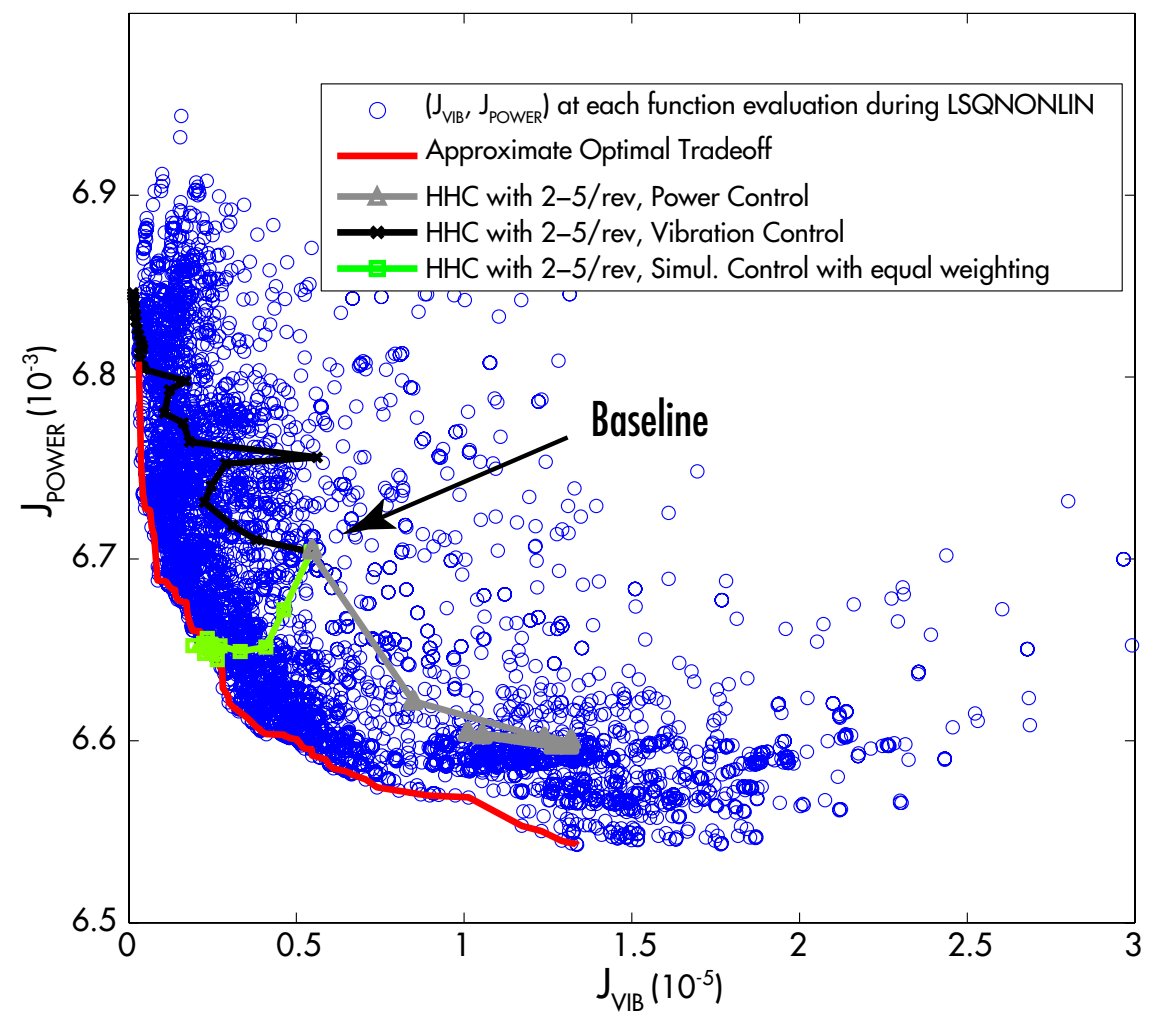

Figure 10. Comparison of optimization history using HHC and LSQNONLIN, showing $\mathbf{J}_{\text {power }}$ vs. $\mathbf{J}_{\text {vib }}, C_{T} / \sigma=$ $0.0714, \mu=0.35$.

\section{E. Effect of Flap Spanwise Locations}

The flap configurations used in the previous sections, as shown in Table 2, are optimized for vibration reduction. Therefore, it is relevant to consider alternative spanwise flap locations which emphasize power reduction. The effect of different spanwise flap locations on the power reduction capability is considered next. This is accomplished by varying the location where a single servo flap is centered. The flap has a span equal to $12 \%$ of rotor radius and its chord is $25 \%$ of the blade chord, which is similar to the single flap configuration in Table 2. Three spanwise locations are considered, as shown in Table 4, where the flap with $x_{c}=0.94 R$ is located at the tip of the blade.

It is interesting that the baseline rotor power is reduced when the flap is moved outboard. The rotor power reduction is somewhat less for the flap centered at $0.85 R$ than for one centered at $0.75 R$ in terms of power reduction percentage. When the flap is located at the blade tip the power reduction is greatest, almost 4\%. However, the optimal flap deflection also alters significantly the rotor trim conditions, in particular rotor thrust. When comparing this characteristic to the flap placed at the other two locations, it is evident that for the inboard location the influence on the rotor trim is negligible. After retrimming the rotor while keeping this optimal flap deflection for power control, the degree of power reduction that can be achieved is reduced to $2 \%$. Therefore, one has to be careful to ensure the similar rotor operating conditions are enforced when conducting power control studies. Finally, it is also important to note that the unsteady aerodynamic model, for attached flow, is not suitable for modeling transonic effects which are known to be important in the blade tip region. 
Table 4. Rotor power reduction with single flap located at various spanwise locations, $C_{T} / \sigma=0.0714, \mu=0.35$.

\begin{tabular}{lccc}
\hline \hline Flap Center $\left(x_{c}\right)$ & $0.75 \mathrm{R}$ & $0.85 \mathrm{R}$ & $0.94 \mathrm{R}$ \\
\hline Baseline Power & 0.00670286 & 0.00663195 & 0.00571054 \\
Controlled & 0.00658692 & 0.00654061 & 0.00548369 \\
Reduction(\%) & 1.73 & 1.38 & 3.97 \\
Power After Retrim & - & - & 0.00559408 \\
Reduction(\%) & - & - & 2.04 \\
\hline \hline
\end{tabular}

\section{F. Comparison of ACF to Conventional IBC for Power Reduction}

Power reduction using the conventional IBC approach is also considered here, so as to compare its effectiveness to the ACF approach. The controller used in the conventional IBC approach is also the adaptive HHC algorithm described earlier. The IBC control inputs also consist of a combination of $2-5 / \mathrm{rev}$ harmonics, similar to that used in the ACF study. Furthermore, the maximum IBC amplitude is restricted to be less than $1^{\circ}$.

Using the conventional IBC approach, the rotor power consumption is reduced to 0.00660756 from the baseline value of 0.00670286 , representing a $1.4 \%$ reduction. This is similar to the reduction achieved using the ACF approach. The vibration levels are significantly increased during power control using IBC as shown in Fig. 11, a phenomenon that was also observed during power reduction studies conducted using the ACF. The IBC time histories for power reduction are shown in Fig. 12.

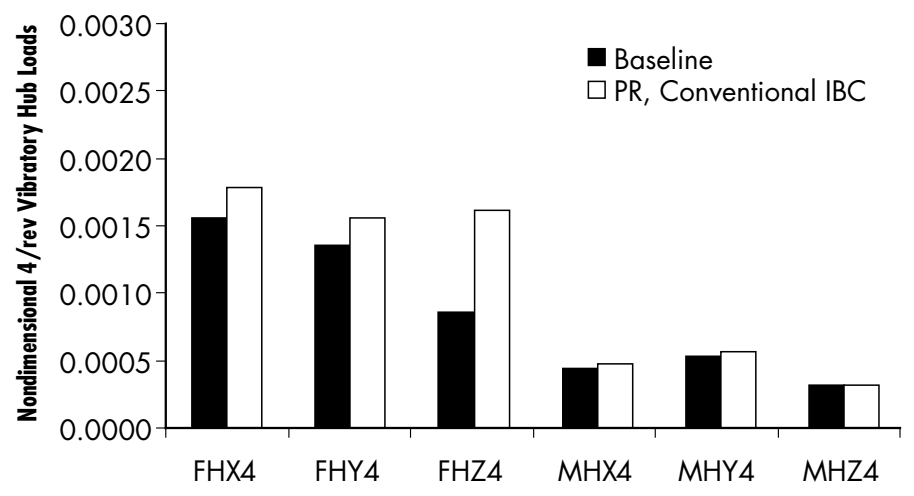

Figure 11. Vibration levels during power reduction using conventional IBC, $\mathbf{C}_{\mathbf{T}} / \sigma=0.0714, \mu=0.35$.

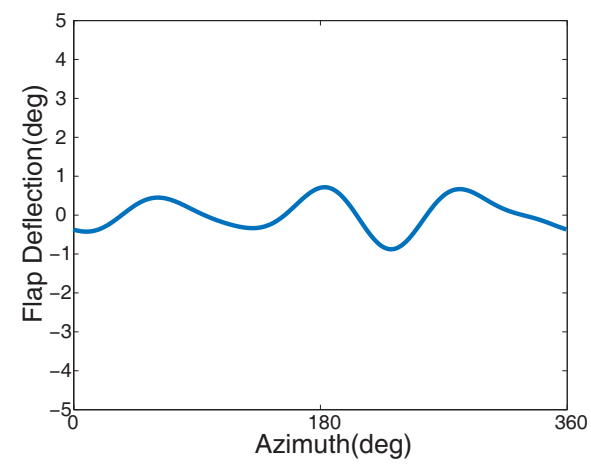

Figure 12. Flap deflection during power reduction using conventional $\mathbf{I B C}, \mathbf{C}_{\mathbf{T}} / \sigma=0.0714, \mu=0.35$. 


\section{G. Vibration and Rotor Power Reduction at Higher Rotor Thrust}

In the previous sections, the results were obtained using a propulsive trim procedure which maintains a rotor thrust coefficient of $C_{T} / \sigma=0.0714$. Vibration and rotor power reduction at higher thrust levels are considered here, at two levels where $C_{T} / \sigma=0.0857$ and 0.1 . These results are obtained using the single flap configuration described in Table 2 , and the advance ratio considered is $\mu=0.35$.

Table 5. Rotor power reduction with single flap at higher rotor thrust levels.

\begin{tabular}{lcccccc}
\hline \hline Rotor Thrust $\left(C_{T} / \sigma\right)$ & \multicolumn{2}{c}{0.0714} & \multicolumn{2}{c}{0.0857} & \multicolumn{2}{c}{0.1} \\
\hline Controller & $\mathrm{PR}^{\dagger}$ & $\mathrm{SR}^{\ddagger}$ & $\mathrm{PR}$ & $\mathrm{SR}$ & $\mathrm{PR}$ & $\mathrm{SR}$ \\
Baseline Power & 0.00670286 & 0.00670286 & 0.00859831 & 0.00859831 & 0.01088269 & 0.01088269 \\
Controlled & 0.00658692 & 0.00667611 & 0.00835513 & 0.00847245 & 0.01045713 & 0.01068480 \\
Reduction(\%) & 1.73 & 0.40 & 2.83 & 1.46 & 3.91 & 1.82 \\
\hline \hline
\end{tabular}

$\dagger$ Power Reduction.

$\ddagger$ Simultaneous Power and Vibration Reduction.

As can be noted from Table 5 , it is evident that the ACF yields a larger power reduction when the rotor is under higher loading. Rotor power can be reduced by $2.83 \%$ when the rotor thrust $C_{T} / \sigma$ is increased to 0.0857 , and almost $4 \%$ at $C_{T} / \sigma=0.1$, compared to the baselines. Similarly when the controller is used to produce simultaneous vibration and power reduction, the power reduction levels that can be achieved are also significantly higher when the rotor disk is more heavily loaded. Vibration levels during power reduction and simultaneous reduction are shown in Fig. 13 and Fig. 14, for $C_{T} / \sigma=0.0857$ and 0.1 , respectively. The vibration levels are generally increased during power reduction, reflecting a trend that has been observed earlier. The combined vibration objective is increased by $10 \%$ when $C_{T} / \sigma=0.0857$, and nearly $50 \%$ when $C_{T} / \sigma=0.1$. By contrast, the vibration objective is reduced by $47 \%$ and $54 \%$ during simultaneous reduction, for $C_{T} / \sigma=0.0857$ and 0.1 , respectively. However, it is noted that the vertical shear component is increased quite significantly when $C_{T} / \sigma=0.1$, although the combined vibration objective is reduced. The corresponding flap deflections for $C_{T} / \sigma=0.0857$ and 0.1 are shown in Figs. 15 and 16, respectively. It is quite interesting to note that the $2 / \mathrm{rev}$ harmonics are the dominant components for power reduction at both rotor thrust levels shown. However, they are surpassed by other harmonics during simultaneous reduction, reflecting a shifted weighting toward vibration reduction.

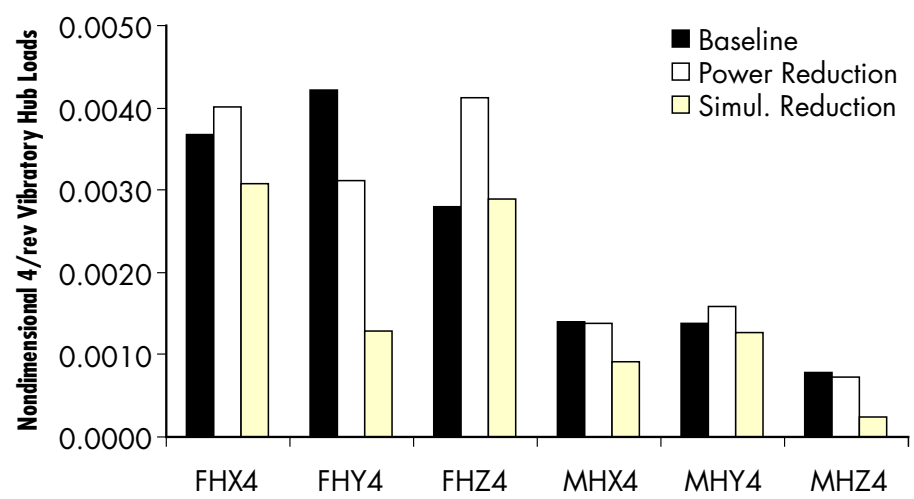

Figure 13. Vibration levels during power reduction and simultaneous reduction, $\mathbf{C}_{\mathbf{T}} / \sigma=\mathbf{0 . 0 8 5 7 ,} \mu=\mathbf{0 . 3 5}$.

\section{H. Vibration and Rotor Power Reduction at Higher Advance Ratio}

In this section the results for vibration and power reduction at an advance ratio of $\mu=0.40$ are presented, in order to gain more insight into the potential of ACF for rotor power reduction. Since at this forward flight speed it was found difficult to maintain the same rotor trim at $C_{T} / \sigma=0.0714$, a value used for the advance 


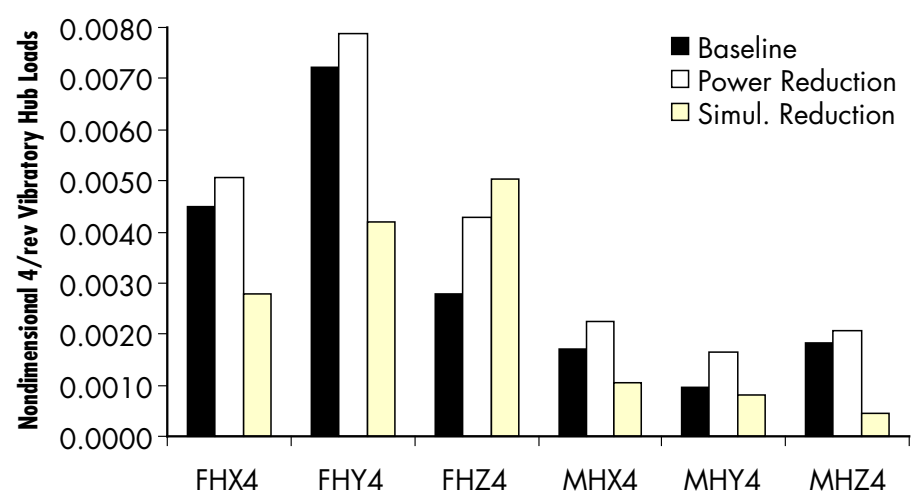

Figure 14. Vibration levels during power reduction and simultaneous reduction, $\mathbf{C}_{\mathbf{T}} / \sigma=0.1, \mu=0.35$.

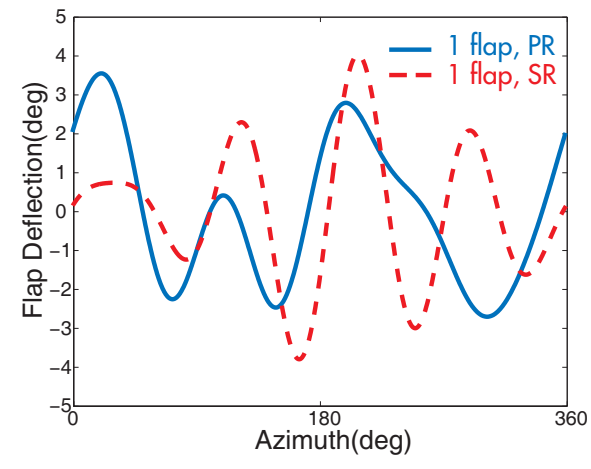

Figure 15. Flap deflection during power reduction and simultaneous reduction, $\mathbf{C}_{\mathbf{T}} / \sigma=0.0857, \mu=0.35$.

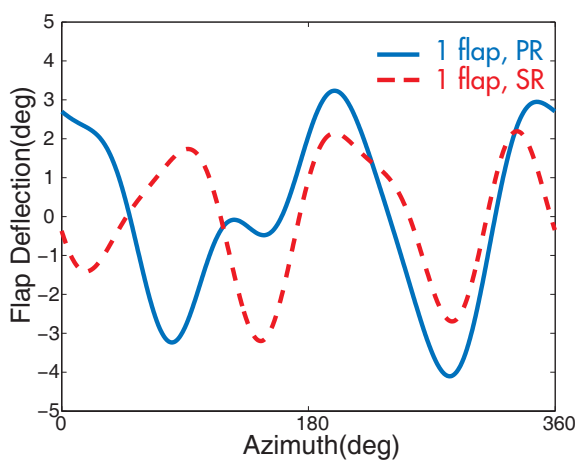

Figure 16. Flap deflection during power reduction and simultaneous reduction, $\mathbf{C}_{\mathbf{T}} / \sigma=0.1, \mu=0.35$. 
ratio of $\mu=0.35$ considered earlier, the rotor thrust $C_{T} / \sigma$ is slightly reduced to 0.0643 , for the advance ratio of $\mu=0.40$.

Table 6. Rotor power reduction with single flap at higher advance ratios.

\begin{tabular}{ccccc}
\hline \hline$\mu$ & \multicolumn{2}{c}{0.35} & \multicolumn{2}{c}{0.40} \\
\hline Controller & PR & SR & PR & SR \\
Baseline Power & 0.00670286 & 0.00670286 & 0.01026845 & 0.01026845 \\
Controlled & 0.00658692 & 0.00667611 & 0.00961412 & 0.00985403 \\
Reduction(\%) & 1.73 & 0.40 & 6.37 & 4.04 \\
\hline \hline
\end{tabular}

From Table 6 it is evident that the ACF is much more effective at power reduction when the rotor is operating at higher advance ratio of $\mu=0.40$. Power reduction of $6.37 \%$ was demonstrated for this flight condition. Even with lower levels of power reduction when simultaneous vibration and power reduction is implemented, the amount of power reduction is still quite sizable at $4 \%$. The corresponding vibration levels are shown in Fig. 17 during both power reduction as well as simultaneous power and vibration reduction. It is interesting to note that the vertical shear components are always increased; however, the combined vibration objectives are reduced for both power and simultaneously reduction cases, by $21 \%$ and $50 \%$, respectively. The flap deflections are shown in Fig. 18. The flap deflection time histories are quite similar for both cases, with dominant components in $2 / \mathrm{rev}$ and $3 / \mathrm{rev}$ harmonics. Compared to the power reduction case, there are more contributions from higher harmonics (4/rev and 5/rev) during simultaneous reduction, in order to suppress vibration.

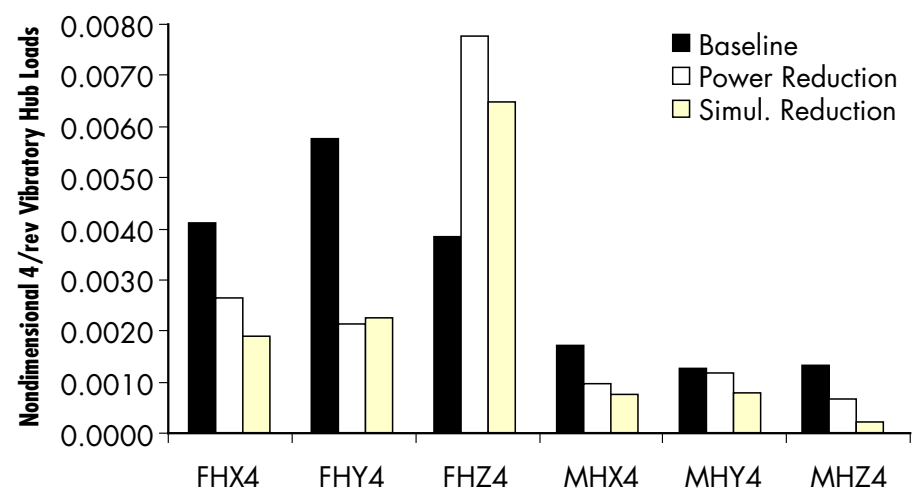

Figure 17. Vibration levels during power reduction and simultaneous reduction, $\mathbf{C}_{\mathbf{T}} / \sigma=0.0643, \mu=0.40$.

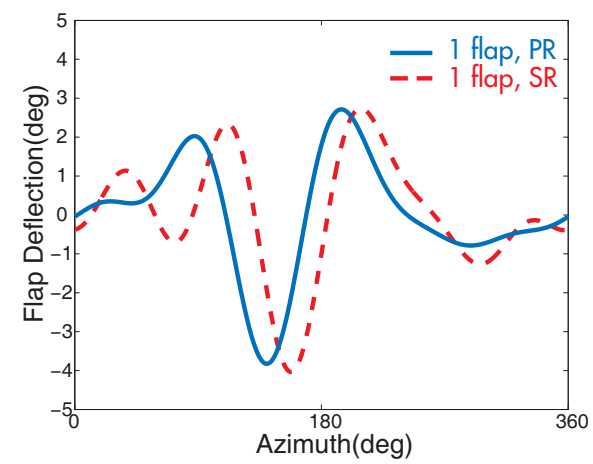

Figure 18. Flap deflection during power reduction and simultaneous reduction, $\mathbf{C}_{\mathbf{T}} / \sigma=0.0643, \mu=0.40$. 


\section{Conclusions}

The results presented in this paper have demonstrated that the ACF system implemented in a single or dual flap configuration is capable of simultaneously reducing vibration and enhancing rotor performance. The numerical simulations are obtained at advance ratios of $\mu=0.35$ and 0.4 where the dynamic stall effects are significant.

The primary conclusions obtained in the course of this study are summarized below:

1. The ACF is an effective device for rotor performance enhancement. Nearly $4 \%$ power reduction is achieved using a rotor configuration that resembles the MBB BO-105 at the advance ratio of 0.35 , and $6.37 \%$ power reduction at the advance ratio of 0.40 .

2. The rotor power reduction can be implemented by using the adaptive HHC algorithm which has been applied successfully for vibration and noise control in previous studies.

3. The rotor power reduction is usually accompanied by a significant increase in vibration levels, if the controller is tuned only for power enhancement.

4. Simultaneous reduction of vibration and rotor power reduction is feasible. For instance, significant vibration reduction of $50 \%$ combined with power reduction of $4 \%$ was found at an advance ratio of 0.40 .

5. The pure $2 /$ rev harmonics may not be the component best suited for power reduction under all circumstances. Other higher harmonic components, particularly $3 /$ rev, can have significant contributions.

6. The ACF approach is more effective for rotor power reduction and simultaneous reduction at higher rotor thrust levels at the advance ratio of $\mu=0.35$. And it is also found to be more effective at the advance ratio of $\mu=0.40$ than at $\mu=0.35$.

7. A nonlinear optimizer LSQNONLIN available in the MATLAB package is also explored for off-line identification of best possible vibration and power reduction. Compared to LSQNONLIN, the adaptive HHC algorithm provides satisfactory performance with superior numerical efficiency, although considerably higher level of power reduction can be achieved using LSQNONLIN.

8. A parametric study of the flap spanwise location indicates that the flap placement near the blade tip can improve power enhancement. However, the rotor trim is affected when the flap is placed near the tip, which requires retrimming the rotor.

9. The ACF system shows power enhancement capability that is comparable to the power enhancement that have been obtained with conventional IBC approach.

\section{Acknowledgments}

This research was supported by the FXB Center for Rotary and Fixed Wing Air Vehicle Design. Partial support of an ARO grant 02-1-0202 with Dr. G. Anderson as grant monitor is acknowledged. Partial support for this project by RITA under WBS: 04-B-01-01.7-A.16 is also acknowledged. The authors want to thank Walter Sonneborn for suggesting that performance be emphasized in conjunction with vibration reduction.

\section{References}

\footnotetext{
${ }^{1}$ Friedmann, P. P. and Millott, T. A., "Vibration Reduction in Rotorcraft Using Active Control: A Comparison of Various Approaches," Journal of Guidance, Control, and Dynamics, Vol. 18, No. 4, July-August 1995, pp. 664-673.

${ }^{2}$ Friedmann, P. P., "Rotary Wing Aeroelasticity - Current Status and Future Trends," AIAA Journal, Vol. 42, No. 10, Oct. 2004, pp. 1953-1972.

${ }^{3}$ Splettstoesser, W., Kube, R., Wagner, W., Seelhorst, U., Boutier, A., Micheli, F., Mercker, E., and Pengel, K., "Key Results From a Higher Harmonic Control Aeroacoustic Rotor Test (HART)," Journal of the American Helicopter Society, Vol. 42, No. 1, Jan. 1997, pp. 58-78.

${ }^{4}$ Jacklin, S. A., "Second Test of a Helicopter Individual Blade Control System in the NASA Ames 40 by 80 Foot Wind Tunnel," Proceedings of the 2nd International American Helicopter Society Aeromechanics Specialists Conference, Bridgeport, CT, Oct. 1995.
} 
${ }^{5}$ Jacklin, S. A., Haber, A., de Simone, G., Norman, T., Kitaplioglu, C., and Shinoda, P., "Full-Scale Wind Tunnel Test of an Individual Blade Control System for a UH-60 Helicopter," Proceedings of the 51st Annual Forum of the American Helicopter Society, Montreal, Canada, June 2002.

${ }^{6}$ Johnson, W., Self-Tuning Regulators for Multicyclic Control of Helicopter Vibrations, NASA Technical Paper 1996, 1982.

${ }^{7}$ Patt, D., Liu, L., Chandrasekar, J., Bernstein, D. S., and Friedmann, P. P., "Higher-Harmonic-Control Algorithm for Helicopter Vibration Reduction Revisited," Journal of Guidance, Control, and Dynamics, Vol. 28, No. 5, September-October 2005, pp. 918-930.

${ }^{8}$ Millott, T. A. and Friedmann, P. P., Vibration Reduction in Helicopter Rotors Using an Actively Controlled Partial Span Trailing Edge Flap Located on the Blade, NASA CR 4611, June 1994.

${ }^{9}$ Myrtle, T. F. and Friedmann, P. P., "Application of a New Compressible Time Domain Aerodynamic Model to Vibration Reduction in Helicopters Using an Actively Controlled Flap," Journal of the American Helicopter Society, Vol. 46, No. 1, Jan. 2001, pp. 32-43.

${ }^{10}$ de Terlizzi, M. and Friedmann, P. P., "Active Control of BVI Induced Vibrations Using a Refined Aerodynamic Model and Experimental Correlation," Proceedings of the 55th Annual Forum of the American Helicopter Society, Montreal, Canada, May 1999.

${ }^{11}$ Depailler, G. and Friedmann, P. P., "Reductions of Vibrations Due to Dynamic Stall in Helicopters Using an Actively Controlled Flap," Proceedings of the 43rd AIAA/ASME/ASCE/AHS/ACS Structures, Structural Dynamics and Materials Conference, Denver, CO, April 2002, AIAA Paper No. 2002-1431.

${ }^{12}$ Depailler, G. and Friedmann, P. P., "Alleviation of Dynamic Stall Induced Vibrations Using Actively Controlled Flaps," Proceedings of the 58th Annual Forum of the American Helicopter Society, Montreal, Canada, June 2002.

${ }^{13}$ Depailler, G. and Friedmann, P. P., "Alleviation Of Rotor Vibrations Induced By Dynamic Stall Using Actively Controlled Flaps With Freeplay," Proceedings of the 28th European Rotorcraft Forum, Bristol, UK, Sept. 2002.

${ }^{14}$ Friedmann, P. P., de Terlizzi, M., and Myrtle, T. F., "New Developments in Vibration Reduction with Actively Controlled Trailing Edge Flaps," Mathematical and Computer Modelling, Vol. 33, 2001, pp. 1055-1083.

${ }^{15}$ Straub, F. K. and Charles, B. D., "Aeroelastic Analysis of Rotors with Trailing Edge Flaps Using Comprehensive Codes," Journal of the American Helicopter Society, Vol. 46, No. 3, July 2001, pp. 192-199.

${ }^{16}$ Koratkar, N. A. and Chopra, I., "Wind Tunnel Testing of a Smart Rotor Model with Trailing Edge Flaps," Journal of the American Helicopter Society, Vol. 47, No. 4, Oct. 2002, pp. 263-272.

${ }^{17}$ Fulton, M. and Ormiston, R. A., "Small-Scale Rotor Experiments with On-Blade Elevons to Reduce Blade Vibratory Loads in Forward Flight," Proceedings of the 54th Annual Forum of the American Helicopter Society, Washington, DC, May 1998, pp. 433-451.

${ }^{18}$ Straub, F. K., Kennedy, D. K., Bomzalski, D. B., Hassan, A. A., Ngo, H., Anand, V. R., and Birchette, T. S., "Smart Material Actuated Rotor Technology - SMART," Proceedings of the 41th Structures, Structural Dynamics and Materials Conference, Atlanta, GA, April 2000, AIAA Paper No. 2000-1715.

${ }^{19}$ Straub, F. K., Kennedy, D. K., Stemple, A. D., Anand, V. R., and Birchette, T. S., "Development and Whirl Tower Test of the SMART Active Flap Rotor," Proceedings of SPIE: Smart Structures and Materials 2004, Vol. 5388, July 2004, pp. 202-212.

${ }^{20}$ Kloeppel, V. and Enenkl, B., "Rotor Blade Control by Active Helicopter Servo Flaps," Proceedings of the International Forum on Aeroelasticity and Structural Dynamics, Munich, Germany, June 28 - July 012005.

${ }^{21}$ Patt, D., Liu, L., and Friedmann, P. P., "Rotorcraft Vibration Reduction and Noise Prediction Using a Unified Aeroelastic Response Simulation," Journal of the American Helicopter Society, Vol. 50, No. 1, Jan. 2005.

${ }^{22}$ Liu, L., Patt, D., and Friedmann, P. P., "Simultaneous Vibration and Noise Reduction in Rotorcraft Using Aeroelastic Simulation," Proceedings of the 60th American Helicopter Society Annual Forum, Baltimore, MD, June 2004, To appear in the Journal of the American Helicopter Society, Vol. 51, No. 2, April 2006.

${ }^{23}$ Patt, D., Liu, L., and Friedmann, P. P., "Achieving Simultaneous Noise and Vibration Reduction Using Simulation," Proceedings of the 30th European Rotorcraft Forum, Marseille, France, September 2004.

${ }^{24}$ Liu, L., Friedmann, P. P., and Patt, D., "Simultaneous Vibration and Noise Reduction in Rotorcraft - Practical Implementation Issues," Proceedings of the 46th AIAA/ASME/ASCE/AHS/ACS Structures, Structural Dynamics and Materials Conference, Austin, TX, April 2005.

${ }^{25}$ Patt, D., Liu, L., and Friedmann, P. P., "Active Flaps for Noise Reduction: A Computational Study," Proceedings of the 61st American Helicopter Society Annual Forum, Grapevine, TX, June 1-3 2005.

${ }^{26}$ Roth, D., "Advanced Vibration Reduction by IBC Technology," Proceedings of the 30th European Rotorcraft Forum, Marseille, France, September 2004.

${ }^{27}$ Shaw, J., Albion, N., Hanker, E. J., and Teal, R. S., "Higher Harmonic Control: Wind Tunnel Demonstration of Fully Effective Vibratory Hub Force Suppression," Journal of the American Helicopter Society, Vol. 34, No. 1, Jan. 1989 , pp. 14-25.

${ }^{28}$ Swanson, S. M., Jacklin, S. A., Blaas, A., Niesl, G., and Kube, R., "Reduction of Helicopter BVI Noise, Vibration, and Power Consumption through Individual Blade Control," Proceedings of the 51st Annual Forum of the American Helicopter Society, Fort Worth, TX, May 1995, pp. 662-680.

${ }^{29}$ Nguyen, K. and Chopra, I., "Effects of Higher Harmonic Control on Rotor Performance and Control Loads," Journal of the American Helicopter Society, Vol. 29, No. 3, May-June 1992.

${ }^{30}$ Cheng, R. P., Theodore, C. R., and Celi, R., "Effects of Two/rev Higher Harmonic Control on Rotor Performance," Journal of the American Helicopter Society, Vol. 48, No. 1, January 2003, pp. 18-27.

${ }^{31}$ Cheng, R. P. and Celi, R., "Optimum Two-Per-Revolution Inputs for Improved Rotor Performance," Journal of Aircraft, Vol. 42, No. 6, November-December 2005, pp. 1409-1417.

${ }^{32}$ Straub, F. K., "Active Flap Control for Vibration Reduction and Performance Improvement," Proceedings of the 51st Annual Forum of the American Helicopter Society, Fort Worth, TX, May 1995, pp. 381-392. 
${ }^{33}$ Schmitz, F. H., Rotor Noise, Aeroacoustics of Flight Vehicles, Vol.1, Acoustical Society of America and American Institute of Physics, New York, 1995, pp. 65-149.

${ }^{34}$ Petot, D., "Differential Equation Modeling of Dynamic Stall," La Recherche Aérospatiale, Vol. 5, 1989, pp. 59-71.

${ }^{35}$ Coleman, T. and Li, Y., "On the Convergence of Reflective Newton Methods for Large-Scale Nonlinear Minimization Subject to Bounds," Mathematical Programming, Vol. 67, No. 2, October 1994, pp. 189-224.

${ }^{36}$ Coleman, T. and Li, Y., "An Interior, Trust Region Approach for Nonlinear Minimization Subject to Bounds," SIAM Journal on Optimization, Vol. 6, 1996, pp. 418-445.

19 of 19 